\title{
Sự khan hiếm nhà ở giá phải rẻ và bài học kinh nghiệm cho Việt Nam từ các nước phát triển trên thế giới
}

\section{The scarcity of affordable housing and lessons for Vietnam from developed countries around the world}

\author{
Phạm Đình Long ${ }^{1 *}$, Nguyễn Huỳnh Mai Trâm ${ }^{1}$ \\ ${ }^{1}$ Trường Đại học Mở Thành phố Hồ Chí Minh, Việt Nam \\ *Tác giả liên hệ, Email: long.pham@ou.edu.vn
}

THÔNG TIN

DOI: 10.46223/HCMCOUJS.

proc.vi.16.1.1861.2021

Ngày nhận: 7/3/2021

Ngày nhận lại: 30/3/2021

Duyệt đăng: 10/4/2021

Tù khóa:

nhà ở giá rẻ, bất động sản Việt Nam, nguyên tắc phát triển nhà ở giá rẻ, bài học kinh nghiệm về nhà giá rẻ

Keywords:

affordable housing, Vietnam's property, principles for developing affordable housing, lessons on affordable housing
TÓM TÁT
Nhà ở giá rẻ là một vấn đề mà nhiều quốc gia trên toàn thế giới đang quan tâm. Các đô thị của Việt Nam đang đối mặt với tình trạng thừa nhà ở cao cấp, thiếu nhà giá rẻ và phải tìm ra nguyên nhân để giải quyết tình trạng này. Đáp ứng nhà ở theo các phân khúc phù hợp cho người dân là một bài toán khó đối với chính phủ Việt Nam cũng như các doanh nghiệp tư nhân bất động sản. Bài viết trình bày thực trạng khan hiếm của thị trường nhà ở giá rẻ ở Việt Nam hiện nay, đồng thời đưa ra những bài học kinh nghiệm quốc tế để Việt Nam xem xét và học hỏi.

ABSTRACT
Affordable housing is an issue that many countries around
the world are concerned about. Vietnam's cities are facing an
excess of luxury homes, lack of affordable housing and have to
find out causes to solve this situation. Meeting housing needs
according to the right segments for the citizens is a difficult
problem for the Vietnamese government as well as private real
estate businesses. The article presents the current scarcity of
domestic affordable housing market and also gives lessons from
international experiences for Vietnam to consider and learn
from.

\section{Giới thiệu}

Thách thức trong việc cung cấp đủ nhà ở giá rẻ là vấn đề mà tất cả các quốc gia ngày nay phải đối mặt, và đặc biệt là ở các đô thị lớn như Hồ Chí Minh, Hà Nội. Trên thực tế, vấn đề này đã xuất hiện trong các mục tiêu chính của Chương trình nghị sự đô thị của Liên hợp quốc (Clos, 2015) và được coi là trọng tâm cơ bản trong hầu hết các nền tảng chính sách của châu Âu (Caturianas, 2020). Ở Việt Nam, không chỉ các lô đất nền nằm ở mặt đường lớn có giá tăng cao mà giá các căn nhà trong hẻm ở khu vực các quận huyện ngoài trung tâm cũng bất ngờ tăng mạnh, thậm chí gấp đôi, gấp ba. Vì thế, cơ hội mua được nhà của người trẻ ngày càng thấp do hầu như thị trường không còn xuất hiện các loại nhà, căn hộ với giá vừa phải, phù hợp với túi tiền. Vấn đề đối với các nhà hoạch định chính sách là phải đưa ra các giải pháp tối ưu để can thiệp, giải quyết vấn đề khan hiếm nhà ở giá rẻ. Do đó, bài báo sẽ nghiên cứu các kinh nghiệm 
thành công từ các quốc gia phát triển trên thế giới được lựa chọn do có những điểm tương đồng với tình hình ở Việt Nam và gợi ý chính sách cho việc phát triển nhà ở giá rẻ.

\section{Cơ sở lý thuyết}

\subsection{Khái niệm}

Nhóm Hội nghị Thượng đỉnh về nhà ở giá cả phải chăng quốc gia Úc (QAHC, 2012) đã phát triển định nghĩa của họ về nhà ở giá rẻ (tiếng anh là affordable housing) là nhà ở "đủ tiêu chuẩn và vị trí hợp lý cho các hộ gia đình có thu nhập thấp hơn hoặc trung bình và không tốn kém đến mức một hộ gia đình khó có thể đáp ứng các nhu cầu trên cơ sở bền vững." Còn nhà ở giá cả rẻ ở Vương quốc Anh bao gồm nhà ở cho thuê xã hội và nhà ở trung cấp, được cung cấp cho các hộ gia đình đủ điều kiện cụ thể mà nhu cầu của thị trường không được đáp ứng (Ministry of Housing, Communities and Local Government, 2011). Hay nhà ở giá rẻ cũng là nhà ở dành cho những người có thu nhập hộ gia đình trung bình trở xuống được chính phủ quốc gia hoặc chính quyền địa phương đánh giá theo chỉ số khả năng chi trả nhà ở được công nhận (Baqutaya và các cộng sự, 2015).

\subsection{Sụ̂ khan hiếm nhà ở giá phải chăng ở Việt Nam}

Giá căn hộ ở các thành phố lớn đang cao gấp vài chục lần so với thu nhập khiến việc sở hữu nhà ở của người dân càng trở nên xa vời. Theo một nghiên cứu của thị trường bất động sản Việt Nam, giá bán căn hộ tại thành phố Hồ Chí Minh hiện nay cao gấp 7 lần thu nhập của lao động thuộc tầng lớp quản lý có kinh tế khá giả, gấp 10 lần so với thu nhập nhóm thu nhập trung lưu, gấp 17 lần so với mức thu nhập của người lao động phổ thông và 28 lần đối với người trẻ mới đi làm (Savills, 2021).

Trong khi đó, theo nghiên cứu của DKRA Việt Nam (2019) cơ hội mua được nhà của người trẻ càng thấp do hầu như thị trường không còn xuất hiện loại căn hộ giá trên dưới 1,1-1,5 tỷ đồng một căn. Cụ thể, trong 3-5 năm trở lại đây, giá căn hộ hạng $\mathrm{C}$ và hạng $\mathrm{B}$ từ mốc $16-21$ triệu đồng mỗi $\mathrm{m}^{2}$ nay đã chạm ngưỡng 25 - 36 triệu đồng mỗi $\mathrm{m}^{2}$. Giá bất động sản không ngừng leo thang đã khiến cơ hội sở hữu nhà ngày càng khó khăn với người trẻ có mức thu nhập từ 15 - 30 triệu đồng mỗi tháng. Đặc biệt, giá nhà trung cấp tại TP.HCM đã chạm ngưỡng 40 45 triệu đồng/ $\mathrm{m}^{2}$, một số dự án 50 - 60 triệu đồng/ $\mathrm{m}^{2}$. Trong khi đó, theo Savills Việt Nam thừa nhận thị trường nhà ở thủ đô cũng đang đối mặt với sự nhảy cảm về giá, ở khu vực ngoài vành đai ba cũng đã có giá tới 60 triệu đồng $/ \mathrm{m}^{2}$. Với thu nhập bình quân đầu người Việt Nam năm nay khoảng $2.750 \mathrm{USD} /$ người (gần 64 triệu đồng/người), giá nhà đang vượt quá xa thu nhập đại đa số người dân (Savills, 2021). Cơ hội mua căn hộ 1 tỷ đồng đang dần "biến mất" với những người trẻ.

Không chỉ các lô đất nền nằm ở mặt đường lớn có giá tăng cao, giá các lô đất nền, căn nhà trong hẻm ở khu vực các quận huyện ngoài trung tâm cũng bất ngờ tăng mạnh, thậm chí gấp đôi, gấp ba. Thời gian gần đây trên các phương tiện thông tin đại chúng thường xuyên nhắc đến tình trạng giá đất nền ở các quận huyện vùng ven như quận 9 , Thủ Đức, Củ Chi, Cần Giờ... bị thổi giá một cách chóng mặt. Xét trong trung và dài hạn, giá nhà đất của Việt Nam được nhìn nhận sẽ tiếp tục đà tăng với mức tăng cao, thấp tùy thuộc vào từng khu vực và từng phân khúc. 


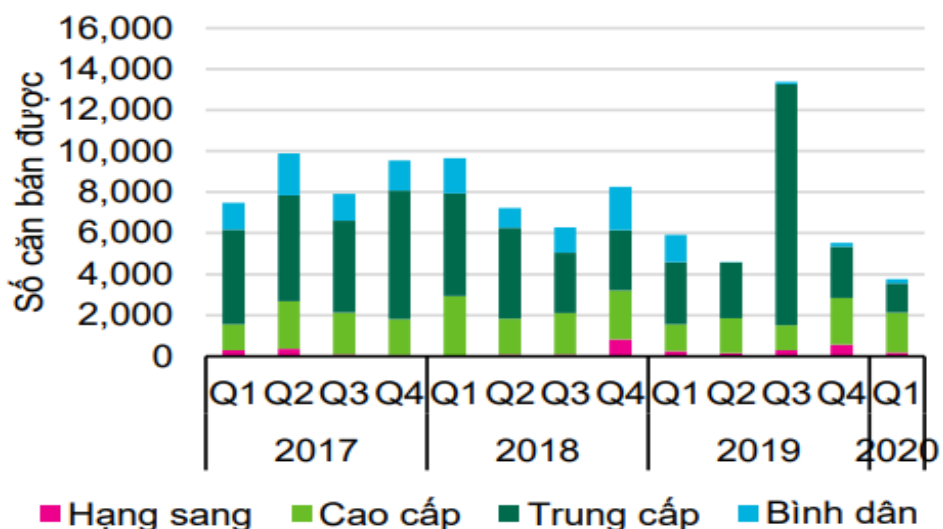

Hình 1. Số dòng căn hộ được bán ở thành phố Hồ Chí Minh

Nguồn: Nghiên cứu CBRE, Quý 1/2020.

Trong Quý 1/2020 có 3.606 căn hộ được chào bán tại 11 dự án, giảm $21 \%$ so với quý trước và $18 \%$ so với cùng kỳ năm trước. Giá bán trung bình tại thị trường sơ cấp ở mức 1.936 $\mathrm{USD} / \mathrm{m}^{2}$, tăng $2 \%$ so với quý trước và $9 \%$ so với cùng kỳ năm trước. Với việc khan hiếm nguồn cung và lượng đặt chỗ vẫn tốt, các chủ đầu tư phân khúc trung cấp có dự án mở bán trong quý đã quyết định tăng giá. Các dự án cao cấp và hạng sang có mức giá ổn định không thay đổi so với quý trước, cao hơn thời điểm cùng kỳ năm trước lần lượt là $6 \%$ và $8 \%$. Trong bối cảnh nguồn cung hạn chế và giá tăng cao thì tình hình tiêu thụ vẫn tốt, đặc biệt là phân khúc trung cấp. Tỷ lệ tiêu thụ cao đạt $80 \%$ đến $100 \%$ được ghi nhận tại một số dự án của chủ đầu tư uy tín. Các dự án nhà ở giá rẻ, phải chăng đang dần biến mất khỏi thị trường. Tình trạng lệch pha cung cầu diễn ra ngày càng rõ rệt, nguồn cung nhà ở thuộc phân khúc trung, cao cấp (trên 25 triệu đồng/m2) đang dư thừa; trong khi nhà ở xã hội và nhà ở thương mại giá rẻ (dưới 25 triệu đồng/m2) lại rất thiếu, dù chiếm tới 70-80\% nhu cầu thị trường (CBRE, 2020).

Qua các số liệu trên Hình 1 và 2 , ta thấy rõ số liệu căn hộ bình dân chỉ ở mức rất thấp so với các phân khúc khác như hạng sang, cao cấp, trung cấp.

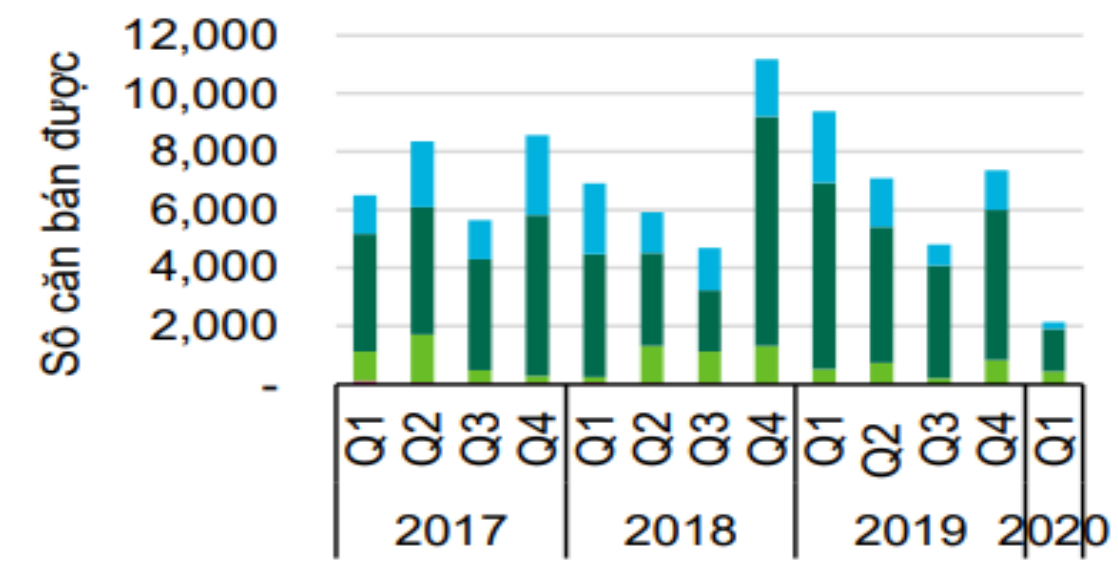

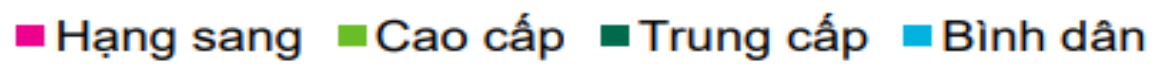

Hình 2. Số dòng căn hộ được bán ở thành phố Hà Nội

Nguồn: Nghiên cứu CBRE, Quý 1/2020. 
Hiện có 4 yếu tố "cổ vũ" cho xu hướng tăng giá bất động sản qua các năm và khiến các doanh nghiệp bất động sản phát triển các phân khúc từ trung cấp trở lên và bỏ qua thị trường nhà ở giá phải chăng.

Thư nhất, nhu cầu BĐS luôn tăng còn diện tích đất không tăng. Dân số hiện tại của Việt Nam là 97,6 triệu người theo số liệu mới nhất từ Liên Hợp Quốc. Đến đầu năm 2021, dân số của Việt Nam dự kiến sẽ đạt 97,8 triệu người. Tác nhân giúp duy trì giá đất chính hiện nay là mật độ dân cư. Những khu vực có tốc độ đô thị hóa cao, giá bất động sản sẽ chỉ tăng chứ không giảm. Điều này tạo nên kịch bản tích trữ đất, gom đất và ôm đất càng nhiều càng tốt. Do nhu cầu tăng lên trong khi nguồn cung hạn chế đã khiến tài sản này ngày càng khan hiếm. Thông thường, cái gì khan hiếm thì giá cao, lập đỉnh và rất khó quay trở về vùng đáy trước đó. Nếu điều kiện kinh tế và chính trị ổn định trong trung và dài hạn, giá bất động sản khó có chuyện đi xuống.

Thư hai, tốc độ phát triển người giàu Việt Nam ngày một nhiều. Việt Nam là quốc gia có tốc độ tăng người siêu giàu nhanh thứ 2 thế giới trong thập kỷ qua. Giai đoạn 2013 -2018 mức độ tăng trưởng người giàu tại Việt Nam là 23\%, giai đoạn 2018 -2023 con số này dự kiến lên đến $28 \%$. Mức độ tăng trưởng dân số siêu giàu có tài sản ròng từ 30 triệu USD trở lên của Việt Nam $2018-2023$ có thể lên đến $31 \%$, thêm $3 \%$ chỉ sau chi kỳ 5 năm (Weath-X, 2019). Khả năng chi trả và nhu cầu sở hữu nhà đất của người Việt ngày càng cao khiến giá nhà khó có chuyện giảm.

Thư $b a$, không bị đánh thuế mua nhà. Một thực tế khác, đó là chính sách điều hành nền kinh tế Việt Nam đang tạo ra những lợi thế nhất định cho thị trường bất động sản nói chung và những nhà đầu tư cá nhân đầu tư vào bất động sản nói riêng. Ở Việt Nam, người mua bất động sản gần như không phải chịu thuế hàng năm, nếu có cũng không đáng kể. Trong khi đó, tại nhiều quốc gia khi mua một bất động sản, hàng năm nhà đầu tư vẫn phải đóng thuế và thuế rất cao dù có lời hay không. Thuế suất khiến nhà đầu tư phải chùn tay khi quyết định mua một bất động sản nếu chỉ để chờ tăng giá mà không khai thác. Những lợi thế do chính sách mang lại đã biến nhà đất trở thành một kênh đầu tư an toàn, có thể đáp ứng một lúc cả ba tiêu chí, giữ tiền an toàn, sinh lời nhiều hơn gửi ngân hàng và có thể bán dễ dàng.

Thứ tux, chi phí liên quan đến đất đai ngày càng lớn. Ngoài tỷ lệ trượt giá, bong bóng giá đất còn tích tụ trong hàng loạt những chi phí khác liên quan đến tài sản này. Đó là xây dựng hạ tầng giao thông và hạ tầng xã hội, chuyển mục đích sử dụng, hoàn tất thủ tục pháp lý... Ngay cả nhân công tăng lên, giá vật tư leo thang, vốn vay làm hạ tầng, chi phí mặt bằng ngày càng đắt đỏ cũng được cộng dồn vào giá đất. Do các chi phí đầu vào hình thành nên tài sản này không ngừng đội lên nên giá đất rất khó sụt giảm về vùng đáy cũ sau mỗi cơn nóng sốt. Tất nhiên, nếu chi phí liên quan đến quá trình hình thành khu đất ở mức cực thấp thì khả năng điều chỉnh giá có thể diễn ra khi thị trường bước vào chu kỳ khủng hoảng. Một cơ sở cho xu hướng tăng giá nhà là sự cải thiện của hệ thống cơ sở hạ tầng.

\section{Các chính sách xây dựng nhà ở giá phải chăng thành công ở các nước phát triển}

Các chính sách được tìm hiểu từ các nước thành công trong việc phát triển các mô hình nhà ở giá rẻ hay ở mức tầm trung phù hợp với khả năng chi trả của các hộ gia đình trong quốc gia đó.

\subsection{Singapore}

Trong sáu thập kỷ kể từ khi Singapore giành được độc lập, nó đã chuyển đổi từ một quốc gia tương đối nghèo với một trong những quốc gia giàu có nhất trên thế giới. Năm 1960, tổng doanh thu của Singapore sản phẩm nội địa trên đầu người chỉ bằng một phần của Hoa (Data.gov.sg, 2015). Ngày nay, theo Ngân hàng Thế giới, GDP bình quân đầu người của Singapore đứng thứ ba cao nhất trong số các quốc gia có chủ quyền trên thế giới (chỉ Qatar và 
Luxembourg cao hơn), và rõ ràng cao hơn so với bất kỳ quốc gia nào trong Khảo sát Khả năng Chi trả cho Nhà ở Quốc tế Demographia (Bertaut, 2019). Việc Singapore cho phép sở hữu nhà rộng rãi đã là một yếu tố quan trọng trong nền kinh tế của nó.

\subsubsection{Cuộc khủng hoảng nhà ở của Singapore}

Vào năm 1960, quốc gia mới phải đối mặt với tình trạng nhà ở nghiêm trọng. Hầu hết các hộ gia đình sống trong "khu ổ chuột không hợp vệ sinh và các khu định cư chật chội đông đúc." Theo Chính phủ Thuộc địa Anh của Singapore năm 1947 Báo cáo của Ủy ban Nhà ở, Singapore từng có một trong những khu ổ chuột tồi tệ nhất thế giới, gọi nó là "một sự ô nhục đối với cộng đồng văn minh" (Kerr, 2005). Giải quyết vấn đề này sẽ là một nhiệm vụ khó khăn.

Không có khu vực đô thị lớn nào trong thế giới thu nhập cao phải đối mặt với thách thức về khả năng chi trả nhà ở Singapore. Sáu triệu người của Singapore sống trên một quốc đảo phát triển đầy đủ, nhỏ đến nỗi nó có thể vừa với một nửa Vịnh Tokyo. Do đó, Singapore thiếu "nguồn cung cấp" chi phí thấp đất ở ngoại ô hoặc ngoại ô có giá nhà vừa phải trên toàn khu vực đô thị. Xa hơn, Singapore là cho đến nay là quốc gia có chủ quyền đông dân cư nhất bên ngoài tiểu bang Monaco. Thật, Singapore có mật độ xấp xỉ 75 phần trăm như thành phố cốt lõi của New York và hơn 50 phần trăm dày đặc hơn London (GLA).

Trên thực tế, địa hình của Singapore và các rào cản quốc tế tạo thành một đô thị cứng nhắc và không linh hoạt. Bên trong ranh giới ngăn đô thị, cần quản lý đất hiệu quả để duy trì nhà ở khả năng chi trả, bởi vì nhu cầu có xu hướng vượt quá cung. Singapore đã quản lý hiệu quả tình trạng khan hiếm cung cấp đất và thiết lập thị trường tạo ra nhà ở có thu nhập trung bình. Theo chỉ số bong bóng bất động sản toàn cầu UBS 2018, "Không có sự khác biệt giữa giá nhà và tăng trưởng thu nhập ở Singapore trong 30 năm qua." (Anthony, 2013).

Điều này trái ngược với các thị trường không có khả năng chi trả nghiêm trọng nhất, chẳng hạn như Úc, Hoa Kỳ, nơi các hộ gia đình có thu nhập trung bình được định giá phần lớn so với mức trung bình giá nhà ở tăng theo chiều xoắn ốc. Điều này là bất chấp nguồn cung đất có thể phát triển của họ rất dồi dào.

\subsubsection{Uu tiên quyền sở hũu nhà và khả năng chi trả của nhà ở}

Singapore đã thành lập Ban Nhà ở và Phát triển (HDB) vào năm 1960 để giải quyết vấn đề. Trong những năm đầu HDB tập trung vào sản xuất nhà cho thuê. Điều này đã và vẫn là điểm nhấn của nhiều chương trình nhà ở thu nhập thấp được trợ cấp trên khắp thế giới. Nhưng tầm nhìn HDB không giam trong nhà bao cấp. Báo cáo thường niên HDB (1964) đã bày tỏ ý định "khuyến khích nền dân chủ sở hữu tài sản ở Singapore và tạo điều kiện cho công dân Singapore ở tầng lớp trung lưu thấp hơn nhóm thu nhập để sở hữu nhà riêng của họ."

HDB đã xem quyền sở hữu nhà là quan trọng để duy trì sự ổn định xã hội và xây dựng các vùng lân cận. Quyền sở hữu nhà cũng được ưa chuộng vì nó khuyến khích tinh thần làm việc giữa các hộ gia đình, vốn cần thiết để tiết kiệm và duy trì ngôi nhà của họ. Singapore coi quyền sở hữu nhà như "nền tảng" của chương trình HDB. Đến năm 1968, chính phủ bắt đầu cho phép người mua tiếp cận các khoản tiền từ an sinh xã hội của họ (Quỹ Nhà cung cấp Trung ương) tài khoản cho cả các khoản thanh toán trước và để hỗ trợ phục vụ thế chấp.

Gần đây hơn năm 2006, chương trình Trợ cấp Nhà ở CPF bổ sung đã được giới thiệu để giúp các gia đình có thu nhập thấp hơn sở hữu những ngôi nhà. Kể từ đó, các khoản trợ cấp khác đã được áp dụng và tăng cường theo thời gian để giúp người mua nhà đủ khả năng mua căn hộ HDB. Với các biện pháp này, người mua sẽ cần sử dụng ít hơn một phần tư thu nhập hô gia đình hàng tháng của họ để trả cho khoản thế chấp căn hộ đầu tiên của họ, một con số thấp hơn so với 
tiêu chuẩn quốc tế cho nhà ở giá rẻ.

Nhà ở HDB được địa phương gọi là "nhà ở công cộng”, nhưng không giống như các chương trình nhà ở công cộng khác. Nhà HDB thuộc sở hữu (hợp đồng thuê dưới 99 năm) của người mua có khả năng bán căn hộ của họ sau năm số năm sử dụng. Thị trường sơ cấp là nhà mới do HDB xây dựng và bán. Các thị trường thứ cấp là doanh số bán của các chủ sở hữu nhà có thể đã mua nhà của họ từ HDB hoặc từ các chủ sở hữu khác. Nhà mới được bán với giá trợ cấp, đây là xu hướng chủ đạo của quốc gia tiếp cận thị trường nhà ở cho các hộ gia đình thu nhập thấp. Bao gồm các hộ gia đình thu nhập thấp hơn trong thị trường nhà ở HDB thu nhập trung bình tránh xã hội sự kỳ thị thường được quan sát thấy ở các quốc gia nơi các khu nhà ở thu nhập thấp tách biệt từ thị trường trung lưu. Điều này đặc biệt quan trọng ở Singapore, nơi mà công dân có trong số các nguồn gốc đa dạng nhất trên thế giới.

HDB đã cung cấp hơn 1.000.000 ngôi nhà tại Singapore, 9/10 trong số đó đã có chủ sở hữu. Kết quả là Singapore là một trong những quốc gia có tỷ lệ sở hữu nhà cao nhất thế giới. Các hậu cấp giá cho trung bình nhà mới có kích thước (khoảng $90 \mathrm{~m}^{2}$ ) gấp 3,3 lần thu nhập trung bình của hộ gia đình (HDB, 2020).

\subsubsection{Các nguyên tắc co bản của Chiến lược $H D B$}

Để đạt được thành công các mục tiêu của mình, HDB đã áp dụng chiến lược nhà ở với ba "nguyên tắc cơ bản quan trọng":

- Khái niệm về một cơ quan duy nhất: Một cơ quan duy nhất phụ trách nhà ở công cộng có hiệu quả hơn trong hoạch định và phân bổ nguồn lực. Khái niệm này làm cho nó có thể đảm bảo đất đai, nguyên liệu thô và nhân lực để xây dựng quy mô lớn nhằm tối ưu hóa kết quả và đạt được hiệu quả kinh tế theo quy mô.

- Cách tiếp cận tổng thể về nhà ở: Bằng cách áp dụng cách tiếp cận tổng thể bao gồm quy hoạch và thiết kế, đất lắp ráp, phát triển và trẻ hóa, nhiệm vụ nhà ở được thực hiện như một tổng thể liền mạch - thông qua phân bổ, quản lý và bảo trì.

- Hỗ trợ mạnh mẽ của chính phủ: Hỗ trợ từ chính phủ dưới hình thức chính trị và tài chính cam kết, được bổ sung bởi luật pháp, đã giúp đưa nhà ở công cộng sớm đi đúng hướng một cách nhanh chóng, đã làm cho quốc gia trở thành một hành trình suôn sẻ và hiệu quả hơn nhiều.

\subsubsection{Mục tiêu xã hội}

HDB cũng tìm cách đạt được các mục tiêu xã hội thông qua các chính sách của mình, chẳng hạn như:

- Thúc đẩy tính lũy tiến bằng cách cấp số tiền trợ cấp cao hơn cho người thu nhập thấp hơn.

- Thúc đẩy hình thành gia đình bằng cách cung cấp số tiền trợ cấp lớn hơn cho các gia đình hơn cho người độc thân.

- Thúc đẩy sự quan tâm và hỗ trợ lẫn nhau bằng cách khuyến khích các gia đình sống cùng hoặc gần cha mẹ của họ hoặc bọn trẻ.

Ngoài ra, chính phủ Singapore đầu tư mạnh mẽ vào việc nâng cấp và đổi mới HDB các vùng lân cận. Điều này giúp ngăn chặn sự suy thoái đô thị ở các khu vực cũ hơn và cho phép tất cả các chủ sở hữu nhà mức thu nhập một môi trường sống chất lượng tương đương với các khu dân cư mới hơn. Trong hơn một nửa thế kỷ, Singapore đã tạo điều kiện hơn cho các hộ gia đình có thu nhập trung bình trên để sở hữu nhà riêng. Chìa khóa quan trọng dẫn đến thành công của 
Singapore nằm ở sự công nhận giá trị về quyền sở hữu nhà đối với hộ gia đình và quốc gia. Hơn nữa, theo HDB, chương trình "đã hỗ trợ đất nước ổn định tổng thể về kinh tế, xã hội và chính trị.” Singapore đã chủ động và ưu tiên thành công việc sở hữu nhà giá rẻ cho công dân của nó, và được phát triển có nghĩa là để hoàn thành mục tiêu đó dựa trên những điều kiện đặc biệt của nó.

\subsection{Hà Lan}

Mặc dù phải đối mặt với các vấn đề tương tự như sống trong một quốc gia đông đúc và đang phát triển, họ đã đạt được một số thành công thông qua việc sử dụng sáng tạo các quan hệ đối tác công tư và các khuôn khổ cho phép rủi ro. Việc mở rộng theo kế hoạch của việc cung cấp một mô hình tốt về cách quản lý tăng trưởng nhà ở để tạo ra các khu định cư mới hấp dẫn và các cộng đồng cân bằng. Nó cũng minh họa cách người Hà Lan đã quản lý để tăng nguồn cung nhà ở quốc gia lên 7,6\% trong mười năm tại khoảng 90 khu định cư mới thông qua Chương trình Nhà ở VINEX, trong khi vẫn cung cấp $30 \%$ số nhà ở giá thuê xã hội (Town \& Country Planning, 2018).

Mặc dù các biện pháp thắt lưng buộc bụng của chính phủ hiện tại đã bắt đầu chuyển lĩnh vực cho thuê xã hội khỏi mục tiêu "chức năng chi trả rộng hơn" và hướng tới "mạng lưới an sinh xã hội”, điều này có thể dẫn đến sự suy giảm truyền thống nhà ở xã hội của Hà Lan, đất nước vẫn cung cấp một số bài học có thể chuyển giao trong việc chủ động cách tiếp cận chính sách nhà ở. Ở từng khu vực của Hà Lan đều hướng tới các chính sách khác nhau để đạt được tỉ lệ nhà ở xã hội cao nhất ở EU.

\subsubsection{Chính sách VINEX}

Chương trình nhà ở VINEX của Hà Lan giai đoạn 1995-2005 đã tạo ra 450.000 ngôi nhà ở một quốc gia có diện tích bằng 1/4 Vương quốc Anh, làm tăng nguồn cung nhà ở lên 7,6\% (Town \& Country Planning, 2018). Chính quyền quốc gia, khu vực và thành phố đã làm việc cùng nhau để đưa ra kế hoạch mở rộng các thị trấn có dân số trên 100.000 người ở những địa điểm có thể tiếp cận bằng phương tiện công cộng - một hệ thống hợp tác ba cấp hiệu quả được ghi nhận trong chính sách phát triển không gian của Hà Lan từ năm 1958. Chính phủ trung ương đã cung cấp trợ cấp cho trang trải chi phí thu hồi đất, khử nhiễm và giao thông công cộng và cơ sở hạ tầng. Khu định cư mới trung bình có khoảng 2.000 ngôi nhà nhưng một số có quy mô lên tới 10.000 ngôi nhà, và được phát triển xung quanh rìa Randstad và nơi đó được gọi là Trái tim xanh nằm giữa các thành phố chính.

VINEX được thay thế vào năm 2006 bởi Nota Ruimte, đây là một chính sách phi tập trung hơn. Các dự án vẫn được điều phối ở cấp quốc gia, nhưng có nhiều quyết định hơn của cấp tỉnh, trong đó chính quyền địa phương được khuyến khích để phát triển nhà ở quy mô nhỏ.

\subsubsection{Khung tụ xây dụng}

Hà Lan đã áp dụng một mô hình tương đương tại Anh. Tự xây nhà và xây nhà theo yêu cầu đã trở nên nổi bật hơn như một trong những cách để giải quyết tình trạng thiếu nhà ở của Vương quốc Anh, với Đạo luật Tự xây và Xây nhà Tùy chỉnh 2015 (UK Legislation, 2015) và Đạo luật Nhà ở và Quy hoạch (2016) (UK Legislation, 2016) yêu cầu chính quyền địa phương lưu giữ sổ đăng ký của những người tự xây dựng địa phương và cấp đủ quyền phát triển cho họ. Kết quả về nhà ở ở các tỉnh của Hà Lan đã cho thấy cách Vương quốc Anh có thể cải thiện khả năng chi trả và tính bền vững của các ngôi nhà, cũng như mở cửa thị trường xây dựng nhà để có khả năng cạnh tranh cao hơn bằng cách áp dụng các khuôn khổ phát triển tự xây dựng. Tuy nhiên, cần lưu ý rằng ở Hà Lan, việc làm này thường chỉ giới hạn ở những người có thu nhập trung bình và cao hơn. 
Điển hình như Almere (một tỉnh ở Hà Lan) được xây dựng trên đất của hội đồng, khiến mục tiêu cung cấp nhà ở với giá cả phù hợp cho các hộ gia đình có thu nhập thấp $€ 20.000$ (£14.500) một năm trở nên khả thi hơn nhiều. Khu vực đầu tiên được quy hoạch tổng thể bởi hội đồng địa phương và được chia thành các quận khác nhau cho nhân khẩu học khác nhau (ví dụ: bền vững, bậc thang, thu nhập thấp hơn). Chính quyền địa phương sau đó đã lắp đặt cơ sở hạ tầng và dịch vụ, và mỗi lô đất được bán với tỷ lệ cố định và đi kèm với một "giấy thông hành" trong đó có danh sách các hạn chế đối với các nhà tự xây dựng tuân thủ các quy định về quy hoạch. Các quy định này quy định về chiều cao, kiểu dáng, mối liên hệ với các lô đất xung quanh và vật liệu, tuy nhiên, mỗi người dân vẫn còn rất nhiều sự sáng tạo và lựa chọn cho phép các ngôi nhà được điều chỉnh theo nhu cầu cụ thể và quy mô gia đình của họ. Điều này mang lại lợi ích lớn trong việc cung cấp các cộng đồng đa dạng và thích nghi với chi phí thấp hơn mà người dân tự hào, tuy nhiên có thể có một số cạm bẫy như thời gian xây dựng lâu hơn và rời rạc hơn.

\subsection{Canada (Vancouver)}

Mục đích của Chiến lược là tối ưu hóa sự đóng góp của thành phố đối với nhà ở giá rẻ để đạt được các mục tiêu về Nhà ở Vancouver đã được sửa đổi và điều chỉnh các phương pháp tiếp cận của chúng tôi với các đối tác để có tác động lớn nhất trong việc phân phối các căn hộ. Chiến lược sẽ thông báo cho các đối tác của chúng tôi về định hướng chiến lược của Thành phố trong việc cung cấp nhà ở giá rẻ trong 10 năm tới, làm rõ các cơ hội hợp tác trong tương lai. Chiến lược đề xuất một cơ cấu phân phối hợp mới nhất dưới hình thức Quỹ hỗ trợ nhà ở giá rẻ được hỗ trợ bởi năm hướng chính để thay đổi cơ chế phân phối nhằm đạt được 12.000 đơn vị nhà ở xã hội và hỗ trợ (bao gồm cả nhà ở chung cư) mười năm tới.

\subsubsection{Làm rõ thách thức về phân phối, tài chính và khoảng cách chính sách}

Trong thập kỷ qua, trước nhu cầu về nhà ở ngày càng tăng và thiếu chiến lược phối hợp giữa các cấp chính quyền, chính quyền đã tăng đáng kể đầu tư vào nhà ở giá rẻ. Cùng với việc đầu tư vốn này, thành phố đã đổi mới và thực hiện các chính sách và chương trình để tăng nguồn cung nhà cho thuê có bảo đảm trên thị trường. Điều này bao gồm việc cung cấp các ưu đãi phát triển cho việc tạo ra $100 \%$ nhà cho thuê, điều này đã khiến thành phố tăng gấp ba lần số đơn vị nhà cho thuê có bảo đảm trên thị trường trong năm năm qua; từ mức trung bình 350 căn cho thuê mỗi năm từ năm 2008 đến 2012 lên 1.100 căn cho thuê mỗi năm từ 2013 đến 2017. Gần đây, thành phố đã khởi động Chương trình thí điểm cho thuê nhà ở cho thu nhập vừa phải nhằm khuyến khích nhà cho thuê dưới giá thị trường.

Một cuộc khảo sát về giá thuê của các dự án được xây dựng ở Vancouver trong thập kỷ qua cho thấy thành phố đã thành công trong việc tăng lựa chọn nhà ở cho các hộ gia đình thuê (cả cá nhân và gia đình) kiếm được 50.000 đến 150.000 đô la/ năm. Trong khi nguồn cung nhà cho thuê ngày càng tăng này đã được hoan nghênh và đáp ứng được nhu cầu của nhiều hộ gia đình có thu nhập trung bình, thì mức độ khả năng chi trả có thể được cung cấp trong các căn nhà cho thuê trên thị trường tiếp tục là một thách thức đối với các hộ gia đình ở nhóm thu nhập thấp hơn. Điều này bao gồm các gia đình và cá nhân có thu nhập dưới 50.000 đô la/ năm, những cá nhân hiện đang vô gia cư và những người có nguy cơ vô gia cư sống trong điều kiện thiếu thốn và không an toàn. Điều này có thể làm mất đi sự đa dạng về thu nhập ở Vancouver: sự thay đổi trong phân bổ thu nhập cho thấy tỷ lệ hộ gia đình thuê nhà có thu nhập dưới 30.000 USD / năm đã giảm từ $34 \%$ năm 2005 xuống $28 \%$ vào năm 2015. Ngoài ra, số người vô gia cư ở thành phố Vancouver năm 2018 cho thấy 2.181 người được xác định là vô gia cư (tăng $2 \%$ so với năm 2017). Những xu hướng này cho thấy một nguy cơ tiềm ẩn đối với sự đa dạng và khả năng phục hồi lâu dài của Thành phố, củng cố nhu cầu đáp ứng các mục tiêu của Bộ Gia cư Vancouver để có nguồn cung nhà ở phù hợp. Nguồn cung cấp phù hợp này bao gồm những ngôi nhà có thể chi 
trả cho những hộ gia đình có thu nhập dưới 50.000 đô la / năm và những người vô gia cư hoặc có nguy cơ vô gia cư. Những hộ gia đình này sẽ yêu cầu các lựa chọn nhà ở xã hội và hỗ trợ và/ hoặc bổ sung tiền thuê nhà.

Nhà ở xã hội và hỗ trợ cũng đòi hỏi đầu tư và trợ cấp bổ sung để có thể phát triển được về mặt tài chính. Thành phố có ba luồng phân phối chính cho nhà ở xã hội và hỗ trợ:

- Đóng góp đất của thành phố - Thành phố cung cấp đất với giá thấp hơn thị trường để phát triển nhà ở giá rẻ hợp tác với các đối tác tài trợ khác.

- Phân vùng tổng hợp - Thành phố cho phép bổ sung mật độ cho các dự án cung cấp tỷ lệ phát triển khu dân cư mới nhất định như nhà ở xã hội.

- Hỗ trợ các dự án khu vực phi lợi nhuận - Thành phố cung cấp vốn và xử lý nhanh cho các dự án nhà ở giá rẻ do các nhà cung cấp nhà ở phi lợi nhuận sở hữu và vận hành ngoài mật độ bổ sung nếu được chính sách hỗ trợ. 


\section{Bảng 1}

Phân tích chi tiết về mục tiêu 10 năm của nhà ở xã hội ở Vancouver

\begin{tabular}{|c|c|}
\hline Loại hình nhà ở & Số lượng \\
\hline Nhà ở xã hội & 5.900 \\
\hline Nhà ở hỗ trợ & 4.100 \\
\hline Nhà ở hợp tác xã & 2.000 \\
\hline Tổng cộng & 12.000 \\
\hline
\end{tabular}

Nguồn: Housing Vancouver (2017).

Trong thập kỷ qua, thành phố đã đều đặn tăng mức đóng góp trong Kế hoạch vốn cho nhà ở từ 18 triệu đô la/ năm trong Kế hoạch vốn 2009-2011, lên 30 triệu đô la/ năm trong Kế hoạch vốn 2012 đến 2014 và 48 triệu đô la/ năm trong năm 2015 lên Kế hoạch vốn năm 2018 (Cox, 2020). Gần đây, hội đồng đã thông qua việc tăng thuế bất động sản $4,24 \%$ như một phần của ngân sách vốn và hoạt động năm 2018 để cân bằng nhu cầu duy trì và cải thiện các dịch vụ của thành phố cũng như đầu tư để đáp ứng nhu cầu trong tương lai cho một thành phố đang phát triển. Khi xây dựng chiến lược này, thành phố đang tiến tới mức đầu tư vào nhà ở giá rẻ, đòi hỏi phải đánh đổi mức độ dịch vụ và đầu tư vốn cho các cơ sở hạ tầng và tiện nghi quan trọng khác.

\subsubsection{Tối ưu hóa bộ công cu thành phố và các vai trò liên quan}

Thành phố đóng vai trò trên ba cương vị chính trong việc giao nhà ở: 1) thành phố có thể hoạt động như một đối tác cổ phần thông qua việc triển khai tài trợ đất và vốn của thành phố cho các dự án nhà ở giá rẻ; 2) với tư cách là người vận động để xác định nhu cầu địa phương và cơ hội đầu tư cho các quan hệ đối tác cấp cao của chính phủ và tài trợ; 3) là cơ quan quản lý để tạo ra chính sách cho phép phát triển mới và tái phát triển các dự án. Với sự tham gia của đối tác, thành phố có thể tập trung tốt hơn vào các vai trò và công cụ phù hợp nhất để thực hiện: cung cấp giám sát quy định và tạo chính sách cho các dự án phát triển nhà ở giá rẻ mới, ủng hộ nhu cầu nhà ở của địa phương cho các cấp chính quyền cấp cao và đóng góp công khai- đất sở hữu để phát triển nhà ở giá rẻ.

\subsubsection{Sư tham gia lai của các cấp chính quyền cấp cao trong việc giao nhà ở}

Trong những thập kỷ trước, khi nguồn vốn của Chính phủ Liên bang và tỉnh sẵn có để phát triển nhà ở giá rẻ, thành phố là một đối tác quan trọng bằng cách cung cấp địa điểm và đóng góp vốn đầu tư khiêm tốn vào các dự án để hỗ trợ khả năng tồn tại. Kết quả của sự hợp tác này là sự gia tăng đáng kể số lượng nhà cho thuê được xây dựng theo mục đích phi thị trường. Kinh nghiệm này cho thấy tầm quan trọng của sự tham gia của chính phủ cấp cao trong việc phát triển nhà ở cho những hộ gia đình vô gia cư, thu nhập thấp và trung bình. Việc ra mắt Chiến lược Nhà ở Quốc gia vào tháng 11 năm 2017 đã đánh dấu một sự thay đổi đáng kể trong chính sách sau nhiều thập kỷ được Chính phủ Liên bang vận động bởi các nhóm nhà ở và báo hiệu sự cam kết trở lại đối với việc giao nhà ở cấp quốc gia. Vào tháng 2 năm 2018, chính quyền tỉnh đã công bố các hướng mới để cung cấp nhà ở giá rẻ với các cam kết tài trợ mới và gia tăng thông qua Kế hoạch 30 điểm về Khả năng chi trả Nhà ở. Những thay đổi này tạo cơ hội cho thành phố tập trung lại việc sử dụng cơ quan quản lý, chính sách, sử dụng đất và các công cụ đầu tư để tối ưu hóa tốt nhất việc cung cấp nhà ở cho các hộ gia đình có thu nhập thấp hơn khi hợp tác với các chính quyền cấp cao, tổ chức phi lợi nhuận và tư nhân các ngành trong tương lai. 
3.3.4. Chính phủ Liên bang: Chiến lược Nhà ở Quốc gia mới và nguồn vốn mới cho nhà ở giá rẻ

Chính phủ Liên bang cung cấp bảo hiểm cho các khoản thế chấp và trợ cấp trực tiếp (tài trợ vốn, tài trợ chi phí thấp, các khoản vay, v.v.) để xây dựng các dự án nhà ở giá rẻ mới và đổi mới các dự án hiện có. Thông qua Chiến lược Nhà ở Quốc gia mới, một số sáng kiến và chương trình tài trợ mới đã được công bố, bao gồm:

- Quỹ đồng đầu tư (ra mắt tháng 5 năm 2018) - Cung cấp 4,7 triệu đô la tài trợ và 8,65 tỷ đô la cho vay để xây mới và sửa chữa các dự án nhà ở xã hội mới và nhà ở xã hội hiện có.

- Sáng kiến Nhà ở Cộng đồng Canada (được Chính phủ Liên bang và Tỉnh thông qua vào tháng 4 năm 2018) - Cung cấp 4,3 tỷ đô la (với chi phí phù hợp của Tỉnh) để đổi mới các dự án nhà ở xã hội hiện có và tạo ra khoảng 50.000 căn nhà ở xã hội mới.

- Tài trợ Uu tiên Lãnh thổ của Tỉnh - Cung cấp 1,1 tỷ đô la (với chi phí phù hợp của Tỉnh) để giải quyết các ưu tiên khác biệt về nhà ở, bao gồm khả năng chi trả, sửa chữa và xây dựng.

Quyền lợi Nhà ở Canada - Cung cấp 2 tỷ đô la để hưởng lợi ích tiền mặt cho các hộ gia đình có thu nhập thấp trong nhà ở xã hội, trong danh sách chờ, hoặc cho thuê trên thị trường.

\subsubsection{Chính quyền cấp tỉnh: Kế hoạch 30 điểm mới và các nguồn vốn mói cho nhà ở giá rẻ}

Chính quyền tỉnh chịu trách nhiệm tài trợ cho các chương trình hỗ trợ thu nhập, các chương trình và dịch vụ hỗ trợ người vô gia cư, cũng như điều tiết và tài trợ cho nhà ở xã hội. Gần đây, Chính phủ đã ban hành một kế hoạch 30 điểm về khả năng chi trả nhà ở, phác thảo các khoản đầu tư mới và các chương trình tài trợ cho nhà ở giá cả rẻ ở British Columbia như một phần của Ngân sách BC 2018. Những sáng kiến này bao gồm:

- Nhà ở xã hội - 445 triệu đô la trong 3 năm để tạo ra 5.000 căn nhà ở xã hội cho thu nhập hỗn hợp mới và tăng khả năng chi trả cho thuê trong 4.900 căn nhà ở xã hội hiện có và đã được quy hoạch.

- Nhà ở Hỗ trợ - \$ 170 triệu cho 2.500 đơn vị nhà ở hỗ trợ và tương ứng với kinh phí hoạt động.

- Nhà ở Tạm thời - 291 triệu đô la trong 2 năm để xây dựng 2.000 đơn vị nhà ở hỗ trợ mô-đun tạm thời (bao gồm 66 triệu đô la tài trợ vốn cam kết cho 600 căn hộ ở Vancouver).

Thông qua chiến lược này, thành phố đang tái tập trung các chính sách, chương trình, đầu tư và cơ chế phân phối nhà ở giá rẻ của mình để tối ưu hóa việc cung cấp nhà, khả năng chi trả và các mục tiêu về căn hộ ở Vancouver. Thành phố sẽ tìm cách giải quyết các thách thức tài chính được xác định ở trên: cung cấp nhà ở ở mức khả năng chi trả sâu hơn cho các hộ gia đình có thu nhập thấp hơn và cư dân đang gặp tình trạng vô gia cư trong khả năng tài chính của thành phố. Cách tiếp cận mới sẽ tập trung vào việc cung cấp đất cho thành phố và các khoản tài trợ vốn khiêm tốn để thúc đẩy quan hệ đối tác chiến lược và đóng góp tài trợ từ các chính phủ cấp cao và các đối tác cộng đồng. Đồng thời, thành phố sẽ tiếp tục sử dụng các công cụ của thành phố để bảo vệ nhà ở giá rẻ hiện có và cho phép tạo ra các lựa chọn cho thuê và sở hữu phù hợp với người dân có thu nhập trung bình. 


\section{Kết luận và khuyến nghị}

\subsection{Kết luận}

Nhà ở giá rẻ ở Việt Nam đang ngày càng khan hiếm trên thị trường bất động sản. Tỷ lệ các căn hộ cao cấp, hạng sang thì tràn lan nhưng những căn hộ, nhà ở hợp giá tiền thì hầu như mất hút. Để có thể giải quyết tình trạng này được xem là câu hỏi khó đặt ra cho chính phủ Việt Nam và các ban ngành. Các nhà lãnh đạo, các doanh nghiệp bất động sản phải nắm được những nguyên tắc cần có khi phát triển các mô hình nhà ở giá rẻ qua việc xem xét và học hỏi các chính sách thành công từ các nước điển hình trên thế giới như Singapore, Hà Lan....

\subsection{Khuyến nghị}

Dựa trên thực tế ở Việt Nam, việc giải quyết các dự án nhà ở giá rẻ đang là vấn đề cấp thiết để ổn định cuộc sống cho nhân dân cả nước. Bài báo gợi mở các gợi ý giải pháp trong việc xây dựng và các phát triển các dự án nhà ở giá rẻ như:

\subsubsection{Tập trung phát triển toàn diện cơ chế pháp lý bất động sản}

Hướng giải quyết tối ưu nhất xuất phát từ các chính sách của Chính phủ. Điểm hạn chế cản trở sự phát triển các dự án nhà ở xã hội giá rẻ ở Việt Nam là việc thiếu sót trong hành lang pháp lý khiến các doanh nghiệp xây dựng ngao ngán. Chính phủ cần tập trung đưa ra các chính sách hỗ trợ các doanh nghiệp xây dựng bất động sản để đẩy nhanh tiến độ xin giấy phép và xây dựng các công trình nhà ở giá trung bình và thấp cho người dân. Các cơ quan, ban ngành cần có những khuyến khích, tuyên dương cho các tập đoàn, công ty xây dựng chung tay phát triển các dự án nhà ở giá rẻ và nhà ở xã hội cho người dân. Đồng thời, Nhà nước nên đầu tư thêm vào cơ sở hạ tầng: cầu đường, trường học, bệnh viện để đồng bộ phát triển các tuyến đường ven thành phố giúp người dân an tâm ổn định cuộc sống. Mỗi dự án được duyệt phải được xem xét kĩ lưỡng trên tổng thể phát triển chung của cả nước và mỗi khu vực. Việc phát triển nhà ở giá rẻ đòi hỏi một viễn cảnh dài hạn và phải tính đến việc tăng thuế tài sản, bảo hiểm và các chi phí liên quan trong tương lai, điều đó có thể làm tăng chi phí hoạt động và dẫn đến dòng tiền âm. Ngoài ra, Nhà nước cũng nên có các chính sách áp thuế mua nhà. Thuế suất khiến nhà đầu tư phải chùn tay khi quyết định mua một bất động sản nếu chỉ để chờ tăng giá mà không khai thác. Khi mua một bất động sản, hàng năm nhà đầu tư vẫn phải đóng thuế và thuế rất cao dù có lời hay không.

\subsubsection{Chọn lựa nhũng địa điểm phát triển dụ án nhà ở giá rẻ}

Các gia đình có thu nhập thấp và trung bình không khác các gia đình khác về mong muốn có nhà ở với các tiện nghi và nhu cầu cơ bản. Theo đó, các chủ đầu tư nên trang bị nhà ở giá cả rẻ để tối đa hóa cơ hội kinh tế và xã hội cho người dân cũng như cho phép các tiện nghi chất lượng cuộc sống, bao gồm việc tiếp cận các trường học tốt, đường phố và công viên an toàn, và các phương tiện giao thông công cộng. Trong quá khứ, các dự án nhà ở giá rẻ thường được chuyển xuống các khu dân cư khó khăn nhất trong thành phố của họ. Việc cô lập nhà ở giá rẻ trong các khu dân cư hẻo lánh với các trường học nghèo nàn và các dịch vụ xã hội kém chất lượng đã hạn chế nghiêm trọng cơ hội đi lên của người dân và khiến người dân và doanh nghiệp không hưởng ứng các dự án nhà ở giá rẻ. Nhà ở giá cả rẻ cũng nên nằm gần các khu bán lẻ, nhà trẻ, trường học chất lượng cao, các trung tâm giải trí, các khu văn phòng và thương mại. Điều này đòi hỏi Chính phủ phải có những dự án tái phát triển lại các khu vực có các dự án nhà ở xã hội giá rẻ.

Một yếu tố có thể ảnh hưởng đến các gia đình có thu nhập thấp hơn các gia đình khác là gần phương tiện giao thông công cộng. Một lợi ích khác của việc tiếp cận với phương tiện giao thông công cộng là nó cho phép chủ đầu tư phân bổ ít không gian hơn cho bãi đậu xe, giúp tăng 
thêm quỹ đất cho nhà ở và giảm chi phí đất tổng thể trên mỗi đơn vị.

\subsubsection{Hạn chế thông tin bất cân xưng để tạo niềm tin của cộng đồng}

Xây dựng sự ủng hộ và lòng tin của cộng đồng bắt đầu bằng việc giao tiếp cởi mở và rõ ràng với tất cả mọi người, từ các cơ quan ban ngành đến những người thực hiện các dự án phát triển và người dân có nhu cầu mua nhà. Quá trình lập kế hoạch và thiết kế công khai và cởi mở cho phép tất cả các bên quan tâm được lắng nghe, đồng thời xây dựng nền tảng quan hệ đối tác và mục tiêu chung trong cộng đồng trước khi đưa ra và thực hiện các quyết định. Các nhà phát triển cũng có thể thúc đẩy sự ủng hộ và tin tưởng bằng cam kết lâu dài trong việc xây dựng và phát triển các dự án.

Thông tin đầy đủ, trực tiếp và chủ động trong quan hệ đối tác với chính quyền địa phương hay các dự án nhà ở giá rẻ phải là một phần của quá trình ngay từ đầu. Các thông tin nên được công bố rộng rãi trên các trang web hiển thị hình ảnh của các giải pháp thiết kế được đề xuất và thông báo ngày và địa điểm của các sự kiện liên quan đến dự án hay các mô hình kiến trúc trên máy tính ảo cung cấp cho cộng đồng cảm giác về sự phát triển đã hoàn thiện sẽ như thế nào và nó sẽ hòa nhập vào cộng đồng hiện tại ra sao. Đồng thời, chương trình sẽ hữu ích khi hỏi các thành viên cộng đồng nơi họ hình dung mình sống trong 10,20 và 50 năm nữa. Bằng cách lắng nghe cộng đồng và đáp ứng tầm nhìn của họ, nhà phát triển có thể tạo ra một kế hoạch phát triển tập trung vào các mục tiêu chung liên quan đến môi trường lành mạnh, nền kinh tế vững mạnh và chất lượng cuộc sống cao.

\subsubsection{Phát triển các quỹ đầu tư nhà ở giá rẻ và chưong trình vay vốn}

Chính phủ cần có những quỹ đầu tư riêng biệt cho việc xây dựng và phát triển các dự án nhà ở giá tầm thấp và trung cho người dân. Bên cạnh đó, Việt Nam cần học hỏi các nước về việc đưa ra các chương trình vay vốn cho người dân cả nước có mong muốn mua các dự án nhà xã hội. Tín dụng thuế nhà ở thu nhập thấp, tài trợ cho khối phát triển cộng đồng cũng như các chương trình khác của chính phủ đại diện cho phần lớn nguồn vốn dự án ở cấp quốc gia. Các quận huyện và thành phố cũng thường cung cấp nhiều chương trình tài trợ và khuyến khích, bao gồm cả quỹ ủy thác nhà ở. Nhìn chung, các dự án nhà ở giá rẻ cần nhiều nguồn vốn khác nhau nên Nhà nước cần phối hợp với các tập đoàn, công ty bất động sản lớn chung tay phát triển các dự án. Việc phát triển nhà ở giá rẻ đòi hỏi kiến thức chuyên sâu về các lựa chọn cũng như khả năng kết hợp tài chính một cách liền mạch để tạo ra một đề xuất phát triển phù hợp.

\section{Tài liệu tham khảo}

Bertaut, A. (2019). 15th annual demographia international housing affordability survey: 2019. Rating middle-income housing affordability. Retrieved September 12, 2020, from https://www.internationalhousingassociation.org/fileUpload_details.aspx?contentTypeID=3 $\&$ contentID $=254954 \&$ subContentID $=726255 \&$ channelID $=38488$

Caturianas, D. (2020). Policies to ensure access to affordable. Retrieved September 13, 2020, from https://www.europarl.europa.eu/RegData/etudes/ATAG/2020/652733/IPOL_ATA(2020)652 733_EN.pdf

CBRE. (2020). Ha Noi City Market View Q1 2020.

CBRE. (2020). Ho Chi Minh City Market View Q1 2020.

Clos, J. (2015). Huoóng dẫn quốc tế về quy hoạch đô thị và vùng lãnh thổ [An international guide to urban and territorial planning]. Nairobi, Kenya : UN Habitat. 
Costarelli, R. K. I. (n.d.). Reframing social mix in affordable housing initiatives in Italy and in the Netherlands. Closing the gap between discourses and practices? The International Journal Of Urban Policy And Planning, 90, 131-140.

Cox, H. P. W. (2020). Demographia international housing affordability. Retrieved September 14, 2020, from http://demographia.com/dhi.pdf

Czischke, G. V. D., \& van Bortel, G. (2018). An exploration of concepts and polices on 'affordable housing' in England, Italy, Poland and The Netherlands. Journal of Housing and the Built Environment, 13-15.

Dalton, T. (2009). Housing policy retrenchment: Australia and Canada compared. SAGE Journals, 46(1), 63-91.

Danko, M. R. (2013). Designing affordable housing for adaptability: Principles, practices, \& application (Bachelor's thesis). Pitzer College, Claremont, CA.

Data.gov.sg. (2015). Total land area of Singapore, January 1, 1960 to December 31, 2019. Retrieved August 13, 2020, from https://data.gov.sg/dataset/total-land-area-of-singapore

Falk, N., \& Rudlin, J. (2018). Learning from international examples of affordable housing. Retrieved August 12, 2020, from https://assets.ctfassets.net/6sxvmndnpn0s/1byrK8fEQut88x9kk4w6cP/0d3452ab160befa27c 832fle1ae83f8e/International_examples_of_affordable_housing__Shelter_URBED_Trust.pdf

Queensland Affordable Housing Consortium (QAHC). (2012). About affordable housing. Retrieved September 17, 2020, from website: https://web.archive.org/web/20120426044505/http://www.qahc.asn.au/modules/tinyd0/index .php?id=8

Gyourko, E. G. J. (2008). Rethinking Federal housing policy. Washington, DC: American Enterprise Institute.

Katz, B. (2003). Rethinking local affordable housing strategies: Lessons from 70 years of policy and practice. Washington, DC: The Urban Institute.

Kerr, T. A. (2005). Nhà ở cho người nghèo ở các nuớc châu Á [Housing for the poor in Asian countries]. Retrieved August 19, 2020, from https://www.unescap.org/sites/default/files/2Low-Income\%20Housing\%20-\%20VN.pdf

Leviten-Reid, C., \& Lake, A. (2016). Building affordable rental housing for seniors: Policy insights from Canada. Journal of Housing For the Elderly, 30(3), 253-270.

Ministry of Housing, Communities and Local Government. (2011). Good practice and guidance, reports and summaries. Retrieved August 11, 2020, from: https://www.gov.uk/government/organisations/ministry-of-housing-communities-and-localgovernment/about/statistics

Paris, C. (2007). International perspectives on planning and affordable housing. Housing Studies, 22(1), 1-9.

Savills. (2021). Báo cáo thị trương bất động sản TPHCM (2020H2VN) [HCMC Real Estate Market Report (2020H2VN)]. Retrieved September 11, 2020, from https://vn.savills.com.vn/research_articles/164027/199209-0

Savills. (2020). HCMC market brief (2020H1EN) - Challenges \& opportunities. Retrieved September 18, 2020, from https://www.savills.com.vn/research_articles/163944/1833430?.ga=2.40816993.235031700.1611322217-379187289.1605398474 
Singapore Housing and Development Board (HDB). (1964). Annual report 1964. Retrieved September 20, 2020, from https://eresources.nlb.gov.sg/printheritage/detail/b4f81d81-cea54307-af6b-63d373beadbb.aspx

The world of Teoalida. (2020). HDB statistics, facts \& figures. Retrieved September 19, 2020, from https://www.teoalida.com/singapore/hdbstatistics/

Town \& Country Planning. (2018). New communities - Looking and learning from Dutch experience. $\quad$ Retrieved August $14, \quad 2020$, from http://urbed.coop/sites/default/files/Looking\%20and\%20learning\%20from\%20dutch\%20exp erience.pdf

UK Legislation. (2015). Đạo luật tụ xây và xây nhà tùy chỉnh 2015 [Self-build and custom housebuilding act 2015]. Retrieved September 15, 2020, from https://www.legislation.gov.uk/ukpga/2015/17/contents/enacted

UK Legislation. (2016). Đạo luật nhà ở và quy hoạch 2016 [Housing and planning act 2016]. Retrieved September 16, 2020, from https://www.legislation.gov.uk/ukpga/2016/22/contents/enacted

Weath-X. (2019). Voice of Vietnam - Vietnam's millionaire population growth among world's fastest. Retrieved August 15, 2020, from https://www.wealthx.com/about-us/pressnews/2019/voice-vietnam-vietnams-millionaire-population-growth-among-worlds-fastest/

Yeong, A. (2013). Affordable and sustainable housing policy - A Singapore perspective. Paper presented at 6th Sabah Surveyor Congress. 